\title{
Supply Chain Management of Aircraft Industry
}

\author{
Yaxin Li \\ Institute of Economics, Shanghai University, Shanghai \\ 18630520575@163.com
}

\begin{abstract}
Keywords: Boeing; Supply Chain; COMAC; Competitiveness
\end{abstract}
\begin{abstract}
The declining demographic dividend requires China's economic and industrial structure to be transformed and upgraded accordingly, and the large aircraft industry, which is the "flower of industry" and technological development locomotive, holds the future of economic transformation and upgrading. This paper studies Boeing from the perspective of supply chain management and analyzes the transition between Boeing and its suppliers from 'build-to-print' relationship to 'design-and-build' relationship. The establishment of medium and large civil aircraft projects has made Chinese enterprises the first to become a governer of the global industrial chain of the aircraft. In order to ensure the sustainable development of the large aircraft business, COMAC should establish a suitable supply chain according to its actual situation Incorporating in a mutually reinforcing manner, each member of the system actively participates in and continuously improves activities to achieve the goal of completely eliminating waste, realizing market value and enhancing competitiveness.
\end{abstract}

\section{Introduction}

As a national industrial level, scientific and technological level and comprehensive strength of a country, the aircraft industry can not only drive major advances in many basic disciplines, but also drive breakthroughs in key technologies such as new materials, modern manufacturing, and electronic information. According to Boeing's research, the output ratio of an aviation project to the local market after 10 years is $1: 80$, the technology transfer ratio is $1: 16$, and the employment-driven ratio is 1:12. Nowadays, when the demographic dividend is constantly disappearing, the development and development of large aircraft has a great effect on promoting industrial transformation and upgrading and enhancing the country's comprehensive strength.

In the Outline of the National Medium and LongTerm Science and Technology Development Plan (2006-2020) promulgated by the State Council of China on February 9, 2006, the large aircraft was identified as one of the 16 major scientific and technological projects that strive to achieve breakthroughs in the next 15 years. In accordance with the major special requirements of the large aircraft project, during the 12th Five-Year Plan period, large-scale aircraft and its ancillary products will be developed, key technical research will be carried out, R\&D standards and normative systems will be established, and a talent team will be formed to realize industrialization during the 13th Five-Year Plan period. On November 2, 2015, the domestic large passenger aircraft C919 completed the final assembly line and successfully made its first flight on May 5, 2017. In the C919 project, 36 domestic colleges and universities, 242 large and medium-sized enterprises, and hundreds of thousands of industrial workers participated in the research and development, and 16 international aviation companies and domestic enterprises are promoted to form 16 joint ventures in order to develop airborne systems such as control, power, fuel, and landing gear.The development of.The relatively complete aircraft industry chain with independent innovation capability and independent intellectual property rights is taking shape with Commercial Aircraft Corporation of China(COMAC) as the core.

Due to the wide range, long cycle, huge investment and high complexity of aircraft development, it is not only a challenge to the level of the aviation industry, but also a challenge to the management. Compared with the centennial Boeing, the management issues facing COMAC are obviously much more complicated, more exploration is needed, and there is a longer way to go for COMAC, more exploration is needed. Based on this, this article explores its supplier management 
model with Boeing, in order to provide a way of thinking for the improvement of the management capabilities of COMAC.

\section{Supply Chain Management of Boeing}

The establishment of Airbus has broken Boeing's monopoly position in the civil aircraft manufacturing industry. As a newly established enterprise, Airbus has adopted a more rational production management method and more advanced materials and technologies. At this time, Boeing faces a lack of methods of managing mixed production types, the contradiction between multi-site and multi-suppliers. In order to solve these problems, and to win in the competition with Airbus, Boeing decided to treat Toyota as a model to reproduce its production process in accordance with the principle of lean production. Boeing traditionally develops products in a serial manner, and purchases raw materials according to the principle of lowest part cost. Most of the production activities are carried out in a Boeing manner, and the production equipment needs to be operated at full capacity to meet the requirements of aircraft delivery[1]. The original supply chain of Boeing is shown in the Figure 1. After the introduction of lean production, Boeing developed products in a parallel manner, procurement was carried out according to the principle of the lowest total cost of products, suppliers began to provide parts and aircraft sub-systems, and gradually participated in the aircraft development process, Boeing will focus on In the overall design and assembly, the use of pull-type production greatly improves the efficiency of aircraft assembly and aircraft quality.

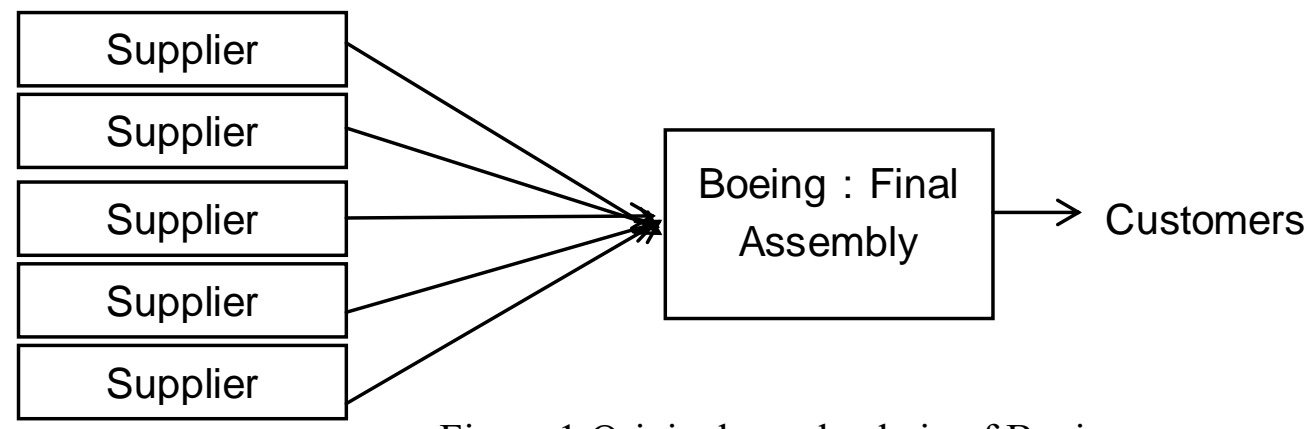

Figure 1 Original supply chain of Boeing

The large civil aircraft consists of three basic components: the fuselage system module, the engine module and the Airborne system module. For airborne equipment, Boeing will cooperate with airborne equipment suppliers in the form of spot procurement when there is no specific requirement. For engine suppliers, due to the capital and technology-intensive characteristics of aircraft engines, the supplier adopts the method of outsourcing the supporting engine since the start of the development of civil aircraft industry. For the supplier of the fuselage parts, as the market competition intensifies, the supplier relationship between Boeing and the suppliers of fuselage parts has undergone three stages of changes: raw material supply, customized subcontracting and strategic partnership cooperation.

In the simple raw material supply stage, Boeing is a highly vertically integrated enterprise. The main production activities are concentrated in Boeing, and the suppliers only provide the corresponding raw materials. For example, B727, only $2 \%$ of the project is outsourced to foreign supply. Business. Starting from B737, Boeing began to cooperate with domestic and foreign suppliers and outsource the subcontract production stage due to the impact of overseas capital prospects and industrial compensation trade policies. From B737 to B757, nearly $50 \%$ of the body parts are produced abroad[2]. At this stage, Boeing designs system-level interface rules. The supplier conducts relevant $R \& D$ and production activities according to the drawings, design and quality requirements provided by Boeing. Assembly and delivery of parts and subsystems from thousands of suppliers. At this time, the relationship between Boeing and the suppliers is only 'build-to-print' trading relationship.

However, in the development of B787, Boeing formed a strategic partnership with about 50 
first-tier suppliers from all over the world, and outsourced about $70 \%$ of manufacturing work to structural suppliers. Mitsubishi, Fuji, and Kawasaki in Japan are responsible for the design and manufacturing of the wing. Italy's Alenia Airlines is responsible for the production of the fuselage part. So Boeing entered the global supply chain stage. As the main system integrator, Boeing only provides high-level interface definitions, the specific design and component manufacturing work of these interfaces is left to the first-tier suppliers independently. Tier 1 suppliers can develop their own supplier networks to complete their respective tasks, and assemble subsystems from their own suppliers as the role of sub-system integrators, and finally Boeing assessbles module components from Tier 1 suppliers[3]. The final assembly is then integrated and delivered, as shown in Figure 2. Boeing's transformation of the supplier management model is based on the following: First, the B787 adopts a large number of advanced technologies and the latest research results of the aviation industry, and adopting global strategic cooperation can share the R\&D risks and costs. Secondly, by distributing the detailed design of aircraft components to Tier 1 suppliers, Boeing can focus its resources on its overall design and system integration which would help to enhance its core competencies. In addition, by connecting outstanding suppliers in different fields, it can acquire a larger market and respond quickly to changes in the environment. B787's global supply chain model marks Boeing's transformation into a system integrator. The relationship between boeing and its suppliers has transformed into 'design-and-build'model. This model has the characteristics of large outsourcing, long chain, wide authorization, high standard, and no borders. Through this, Boeing has achieved long-term returns such as reducing R\&D cycles and risks and saving R\&D expenses.

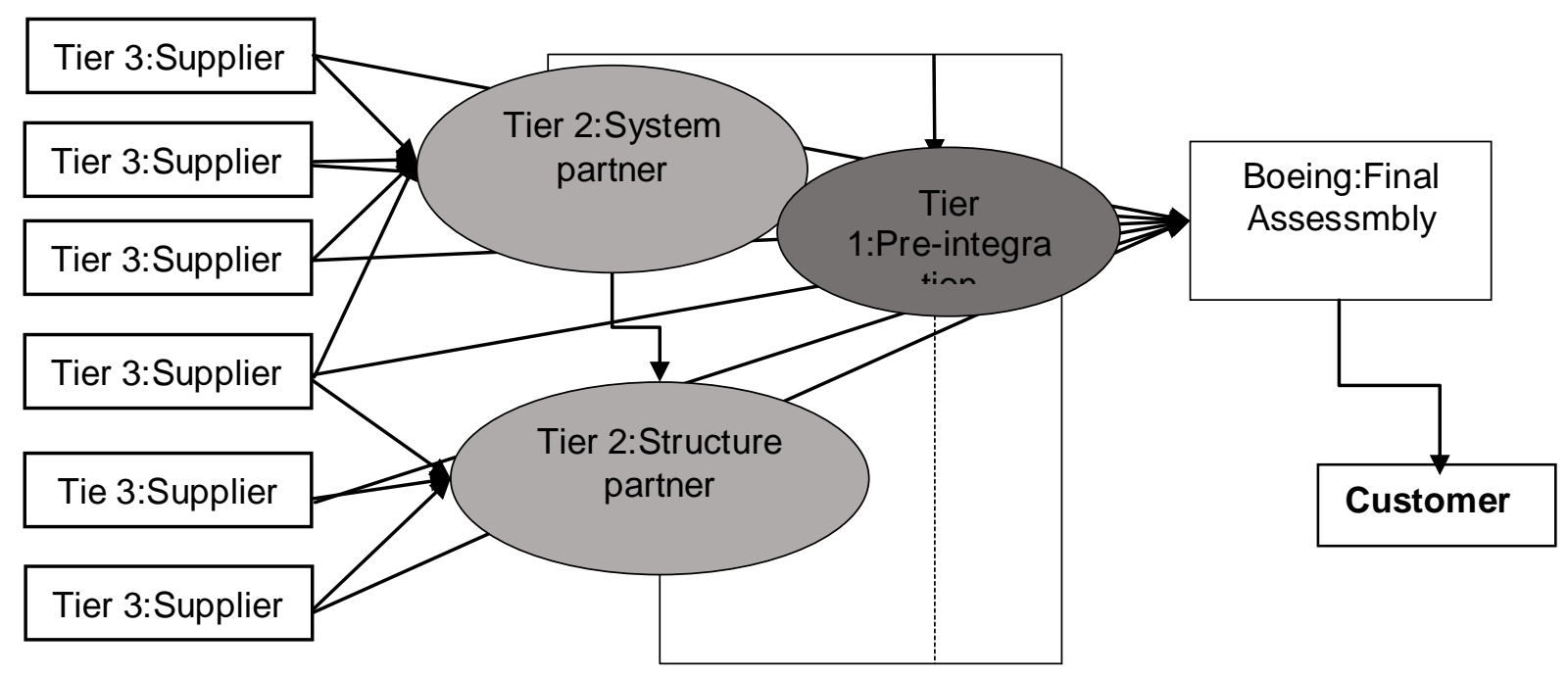

Figure 2 New supply chain of Boeing

The organizational structure represents the integration mechanism between the enterprise and its suppliers for coordinating activities, while the product architecture represents the decomposition of product subcomponents and their interactions[4]. When the product architecture is modular, it is not difficult to integrate external suppliers. But when there are significant uncertainties in the interdependence of subcomponents, such as complex products involving cutting-edge technologies a holistic organizational structure should be used, that is breakthrough innovations in the overall product need to be cross-team Close communication and integration. The organizational capability of the enterprise supplier system is an extension of the internal product development and production system. The author believes that Boeing has two methods for managing suppliers: risk sharing plan, and production integration center.

Risk sharing plan. In a lean and collaborative environment, Boeing and its Tier 1 suppliers are strategic partnerships that share risks and common profits. Boeing requires its Tier 1 suppliers to invest their own funds and resources for engineering development and integration. The resulting intellectual property is owned by the designer, and the Tier 1 supplier can also receive a percentage 
of the revenue commission after the aircraft is handed over to the customer. Through the risk sharing plan, not only can the initial investment and R\&D risks of the main manufacturer's aircraft R\&D project be reduced, but also facilitate the promotion of collaborative relationships, facilitate the exchange of information between trading companies, and encourage partners to innovate to improve the entire system. Dynamically enhance the international competitiveness of Boeing.

Production Integration Center. In order to strengthen the immediate control of the global supply chain, Boeing found and solved the problems of production systems in time to achieve on-time production. Boeing established the Production Integration Center (PIC) in December 2008 for the 787 project. The PIC is a 5,100 square foot center that operates around the clock and has translations in 28 different languages. The center consists of experts in different functional areas, including aircraft design, avionics, structure, technology, assembly and logistics. The main functions are as follows.

One function is that it could integrated production. By installing a high-definition camera at the partner's production site, Boeing can learn about the partner's production process, monitor the partner's product level and anticipate possible delays. One function is to Solve suppliers problem. Once a partner has problems in production, the center can contact Boeing experts in the relevant areas to solve the problem in a timely manner; and as the number of partner contacts increases, the management will give priority to it. The third function is to coordinate transportation. Monitor the delivery status of a wide range of components from around the world, through which Boeing can reduce inventory levels in the product. The last one is to monitoring potential threats. Surveillance of incidents that may affect the supply of components, such as earthquakes, strikes, etc., ensures that Boeing 787 components are shipped to the final assembly destination[5].

Paying attention to the supplier's production quality, cost, schedule, flexibility, stability, and real-time monitoring of these indicators, turning the post-action control into the control of the event and even the prevention beforehand is an important idea of lean management[6]. The Production Integration Center actually regulates and grasps the entire supply chain from a macro perspective, increases the transparency of knowledge and activities between Boeing and suppliers, enables suppliers to solve problems in a timely manner, and Boeing can also learn about partners. The production process responds to possible delays.

\section{The supply chain management of COMAC}

As the executor of the medium and large civil aircraft project, COMAC was established in Shanghai, China on May 11, 2008, which coordinate the development of civil aircraft and realize the task of industrialization of national aircraft. Based on the large aircraft industry chain is a producer-driven model, the industrial chain governance rights are in the hands of companies who undertake R\&D design and final assessmley capabilities, so COMAC focuses its attention on aircraft R\&D, final assembly manufacturing, marketing, and customers. in order to achieve the governance of the new value chain of China's large aircraft industry. In the development of the C919 passenger aircraft, COMAC has implemented the "main manufacturer-supplier" development model, and COMAC has mastered the key aspects of the overall design, final assembly and flight test of the aircraft. According to the supplier's research and development capabilities, the main manufacturing tasks of the body components are mainly undertaken by domestic enterprises, such as AVIC and Baosteel Group, while the engine and airborne systems are provided by 16 multinational companies in the United States, Germany, Switzerland, France and other countries. The way of their participation is mainly to establish 16 joint ventures with AVIC, China Electric Power Company in the field of airborne systems such as avionics, flight control, power supply, fuel oil and landing gear.the aim of approach is to gradually improve the level of manufacturing through technology transfer, diffusion and spillover. The domestic suppliers of COMAC is shown inTable 1 
Table 1 Domestic suppliers of COMAC

\begin{tabular}{|c|c|c|}
\hline Name & Order & $\begin{array}{l}\text { Parent } \\
\text { Company }\end{array}$ \\
\hline $\begin{array}{l}\text { The Research Institute } \\
\text { for Special Structures of } \\
\text { Aeronautical } \\
\text { Composite(RISAC) } \\
\text { AVIC }\end{array}$ & $\begin{array}{l}\text { Design, manufacturing, testing of } \\
\text { radome and Airworthiness Certificate }\end{array}$ & \multirow{7}{*}{$\begin{array}{l}\text { Aviation } \\
\text { Industry } \\
\text { Corporation of } \\
\text { China }\end{array}$} \\
\hline $\begin{array}{l}\text { AVIC Xi'an Aircraft } \\
\text { Industry (Group) } \\
\text { Company Ltd }\end{array}$ & $\begin{array}{l}\text { Manufacturing of fuselage (including the } \\
\text { Central Wing),outer warily box } \\
\text { (including a fixed front and rear } \\
\text { edge),flaps, trailing edge flaps, leading } \\
\text { edge slats and spoilers }\end{array}$ & \\
\hline $\begin{array}{l}\text { Shenfei Civil Aircraft } \\
\text { Company Ltd }\end{array}$ & $\begin{array}{l}\text { Design the fuselage tail with COMAC } \\
\text { together }\end{array}$ & \\
\hline $\begin{array}{l}\text { Chengdu Aircraft } \\
\text { Industry ( Group ) } \\
\text { Company Ltd }\end{array}$ & Manufacturing of aircraft nose & \\
\hline $\begin{array}{l}\text { Harbin Aircraft Industry } \\
\text { ( Group ) Co. Ltd }\end{array}$ & Providing composite on airframe & \\
\hline $\begin{array}{l}\text { Hongdu Aviation } \\
\text { Industry Group Ltd }\end{array}$ & $\begin{array}{l}\text { Manufacturing of forward fuselage and } \\
\text { aft fuselage structure }\end{array}$ & \\
\hline $\begin{array}{l}\text { Changhe Aircraft } \\
\text { Industry Group Ltd }\end{array}$ & $\begin{array}{l}\text { Research and manufacturing of wing } \\
\text { spoiler and other parts }\end{array}$ & \\
\hline $\begin{array}{l}\text { The Research Institute } \\
\text { for Special Material and } \\
\text { technology of } \\
\text { Aeronautical }\end{array}$ & $\begin{array}{l}\text { Providing four packages including } \\
\text { winglets, aileron, spoiler and aft fuselage } \\
\text { caudal }\end{array}$ & $\begin{array}{c}\text { China } \\
\text { Aerospace } \\
\text { Science and } \\
\text { Industry Corp. }\end{array}$ \\
\hline Xizi UHC & Provision of non-hermetic doors & $\begin{array}{l}\text { Private } \\
\text { Company }\end{array}$ \\
\hline
\end{tabular}

According to the "13th Five-Year Plan for the Development of the Company" and the "Outline of the Company's Medium and Long-Term Development Strategy (2016-2030)", China Commercial Aircraft will enter the rapid growth period from the introduction period and will transform from Product development-oriented to the model which treats product development as the base and gradually realize product management. COMACwill focus on the development of aircraft products business, aviation finance business, asset management business, aircraft customer service and maintenance modification business and aviation operation business. The challenges COMAC facing today include: getting rid of Western countries' blockade of core technology, perfecting, maturing supply chain systems, and establishing efficient production systems. As a latecomer, COMAC needs to absorb Boeing's experience in supply chain management and take advantage of its latecomer to actively establish a effective supply chain management system.

The current competition in the aircraft industry is not only the competition between aircraft manufacturers, but also the supply chain competition dominated by the main manufacturers. The current risk cooperation mode has become an emerging form of division of labor for the large aircraft industry, and it is still a trend of commercial aircraft supply chain coordination for a long time[7]. There are three main ways in which COMAC and C919 passenger aircraft suppliers can cooperate. The first is a strategic partnership with the engine supplier; the second is a risk partnership with system suppliers such as avionics, flight controls, and landing gear, and the risk partnership requires the supplier to bear part of the R\&D expenses; The three types are the trading relationship with the general suppliers. The general suppliers do not participate in the aircraft 
development task, only provide raw materials, standard parts and so on. The large aircraft project has made China the first time to become the global supply chain manager of the aircraft industry, and still has a long way to go in the selection and management of suppliers. First, we should improve the organization of supplier management, establish a sound standard and process for supplier selection. Secondly, we should foster mutual trust and mutual communication between member companies. The main manufacturer should establish risks with suppliers through various channels. A partnership with a total of profit and loss, forming a symbiotic whole with suppliers.

\section{References}

[1] T. Song, Y. Li, J.S. Song and Z. Zhang: Procedia Engineering, 2014 No.80,P.628-637.

[2] M. X. Jiang, Y. L. Zhang and Y. F. Xu: Aeronautical Manufacturing Technology, 2010 No.24, P102-105.

[3] C. S Tang, J. D, Zimmerman, J. I, Nelson: Supply Chain Forum An International Journal,Vol. 10 (2009) No.2, P74-86.

[4] X. W. Zhang, J. Chen, H. Tian: Technology Economics, Vol. 36 (2017) No.10, P9-13.

[5] S. Kotha, K. Srikanth: Global Strategy Journal, Vol. 3 (2013) No.1, P41-46.

[6] H. Huang, X. Wu and L. Shi: Science and Technology Management Research, Vol. 2 (2012) No.2, P71-74.

[7] J. L. Zhang, T, Shang: Journal of Beijing Institute of Technology ( Social Sciences Edition ), Vol. 13 (2011) No.6, P63-67. 